\title{
Agendas da educação básica: gestão escolar e qualidade da educação
}

\author{
Agendas of basic education: school management and quality in education \\ Agendas de la educación básica: gestión escolar y calidad de la educación
}

ROSIMAR SERENA SIQUEIRA ESQUINSANI CARMEM LÚCIA ALBRECHT DA SILVEIRA

\begin{abstract}
Resumo: O texto discute as estruturas e dinâmicas da gestão escolar e seu vínculo com a qualidade da educação. Como metodologia, adotou a pesquisa em fontes documentais e foi desenvolvida em uma rede pública de educação básica de um município no interior do Rio Grande do Sul, ao longo de quatro anos (2010-2014). Os achados da pesquisa problematizam os vínculos entre a gestão escolar e a qualidade da educação, sendo que os mesmos são de ordem endógena: práticas de gestão, sujeitos e cotidiano escolar; e exógena: estruturas burocráticas, avaliações em larga escala e formação docente.
\end{abstract}

Palavras chave: Gestão escolar; qualidade da educação; educação básica.

\begin{abstract}
The text presents research which discusses the structures and dynamics of school management and its link with the quality of education. As methodology, it adopted research in documentary sources, it was developed in public primary education schools in a town of Rio Grande do Sul, over four years (2010-2014). The research findings problematize the links between the school management and the quality of education, and they are of endogenous order: management practices, subjects and school routine; and exogenous: bureaucratic structures, large-scale assessments and teacher training.
\end{abstract}

Keywords: School management; quality of education; basic education.

Resumen: El texto presenta pesquisa que objetivó discutir las estructuras y dinámicas de la gestión escolar y su vínculo con la calidad de la educación. Como metodología, adopto la pesquisa en fuentes documentales, desarrollada en una red pública de educación básica de un municipio en el interior del Rio Grande del Sur, a lo largo de cuatro años (2010-2014). Los hallados de la pesquisa problematizan los vínculos entre la gestión escolar y la cualidad de la educación, siendo que los mismos son de orden endógena: prácticas de gestión, sujetos y cotidiano escolar; y exógena: estructuras burocráticas, evaluaciones en amplia escala y formación docente.

Palabras clave: Gestión escolar; calidad de la educación; educación básica. 


\section{INTRODUÇÃO}

A escola de Educação básica, no Brasil, organiza-se a partir de diretrizes comuns estabelecidas pela legislação vigente, mormente a Lei 9.394/1996. Com algumas variações previstas em lei (incluindo possíveis alterações de calendário e nomenclatura), a escola de Educação Básica como instituição respeita parâmetros que transcendem espaços geográficos e funciona, em sua formalidade, de maneira semelhante em todo o território nacional. Nas palavras de Licínio Lima: "a escola jurídico-formal é singular, perfeitamente definida dentro dos limites da lei, geral e abstracta, indiferente às diferenças dos contextos, dos actores e das suas dinâmicas de interacção" (2008, p.85).

Mas, os processos cotidianos que ocorrem, no interior das escolas, obedecem a alterações robustas e singulares, uma vez que esses processos, sim, levam em conta atores e dinâmicas de interação, considerando aspectos como: currículo, demandas locais, constituição do corpo docente, dependência administrativa, financiamento e, principalmente, as estruturas e dinâmicas próprias da gestão escolar de cada unidade educativa pois, nesta perspectiva, "cada escola é um contexto específico de acção, certamente marcado por dimensões políticas, jurídicas, formais e estruturais de diversos tipos, mas também pelas capacidades de agenciamento e intervenção dos actores individuais e colectivos" (LIMA, 2008, p.86).

Este texto discute as estruturas e dinâmicas da gestão escolar e seu vínculo com a qualidade da educação, pois as mesmas configuram-se como alterações palpáveis na 'cultura escolar'. Assim, o texto apresenta resultados conclusivos de uma pesquisa, que teve como objeto justamente a relação entre a gestão escolar e a qualidade da educação básica.

O problema de pesquisa concentrou-se em descrever e discutir indicadores que explicitassem os possíveis vínculos entre as dinâmicas da gestão escolar com a qualidade da educação, entendendo que estes vínculos seriam oriundos de situações multifatoriais que, por seu turno, concorreriam para a produção de indicadores igualmente multifatoriais e orgânicos. Assim, discutir o vínculo entre gestão escolar e qualidade da educação, consiste em colocar-se diante de um fenômeno de natureza dialética, que não tem uma única origem, tampouco pode ser explicado por uma única matriz.

Há certa confluência na compreensão de que a qualidade da educação não pode ser atribuída a uma única condição ou dimensão, pois que...

A qualidade de um sistema educacional resulta de um complexo conjunto de fatores em que estão presentes desde elementos mais objetivos como aspectos materiais relativos ao provimento de serviços (a exemplo de prédios, 
equipamentos e livros) a outros menos tangíveis (como a liderança da equipe dirigente, a motivação da comunidade escolar, etc.) (VIEIRA, 2009, p.106, grifos nossos).

Assim, o trabalho em relevo insere-se na perspectiva de discutir a gestão escolar como um dos fatores que vincula a qualidade da educação, discutindo relacionalmente a produção de indicadores para a análise deste vínculo.

\section{SOBRE A METODOLOGIA}

Pela característica multifacetada do objeto, a metodologia foi estruturada a partir de uma pesquisa empírica desenvolvida em uma rede pública municipal de educação básica de um município de porte médio no interior do Rio Grande do Sul, ao longo dos últimos cinco anos (2010-2014). O recorte de trabalho ainda privilegiou os dados advindos das 35 (trinta e cinco) escolas de ensino fundamental da rede em tela.

Do ponto de vista conceitual, entende-se que o estudo empenhado subordina-se às pesquisas de caráter qualitativo, uma vez que...

A pesquisa qualitativa responde a questões muito particulares. Ela se preocupa, nas ciências sociais, com um nível de realidade que não pode ser quantificado. Ou seja, com o universo de significados, motivos, aspirações, crenças, valores e atitudes, o que corresponde a um espaço mais profundo das relações dos processos e dos fenômenos que não podem ser reduzidos à operacionalização de variáveis (MINAYO, 2002, p. 21-22).

Este universo de significados foi desnudando as perguntas de pesquisa a partir da análise de conteúdo de documentos circunscritos à rede em exame. Assim, foram selecionados, em face ao escopo da pesquisa, os seguintes documentos empíricos: a) atas de reuniões realizadas entre a mantenedora e as escolas da rede de ensino, entre 2010 e 2013; b) questionários próprios, elaborados a partir dos objetivos da pesquisa e aplicados aos gestores escolares nos anos de 2011 e 2012; c) pesquisa de opinião aplicada a todos os professores da rede nos anos de 2013 e 2014; d) relatórios anuais, entregues pelas escolas ao final de cada ano letivo do recorte temporal estabelecido, contendo os principais acontecimentos e as percepções/avaliações dos gestores sobre o cotidiano da escola; e) calendários escolares organizados por cada escola, entre os anos de 2010 e 2014 e, por fim; f) resultados das avaliações em larga escala refletidos também nos índices de aprovação/reprovação/evasão e no IDEB de cada escola.

Acredita-se que estas fontes documentais acenariam com a possibilidade de descortinar a cultura escolar, entendida como: 
um conjunto de normas que definem conhecimentos a ensinar e condutas a inculcar, e um conjunto de práticas que permitem a transmissão desses conhecimentos e a incorporação desses comportamentos; normas e práticas coordenadas a finalidades que podem variar segundo as épocas (finalidades religiosas, sociopolíticas ou simplesmente de socialização). Normas e práticas não podem ser analisadas sem se levar em conta o corpo profissional dos agentes que são chamados a obedecer a essas ordens e, portanto, a utilizar dispositivos pedagógicos encarregados de facilitar sua aplicação, a saber, os professores primários e os demais professores. Mas, para além dos limites da escola, pode-se buscar identificar em um sentido mais amplo, modos de pensar e de agir largamente difundidos no interior de nossas sociedades, modos que não concebem a aquisição de conhecimentos e de habilidades senão por intermédio de processos formais de escolarização (JULIA, 2001, p. 10-11).

Assim, a condição multifatorial do objeto de estudos, associa-se à condição igualmente multifatorial das elaborações da cultura escolar, ampliando o leque de possibilidades, análises e, consequentemente, a necessidade de dados advindos dos mais distintos documentos.

No que diz respeito às atas de reuniões entre a mantenedora e as escolas da rede, foi possível coletar dados em relação aos principais eventos que envolviam as referidas escolas e seus processos de gestão como, por exemplo: projetos e programas de governo; discussões sobre calendário escolar; participação em eventos de formação docente continuada; encaminhamento de situações administrativas e burocráticas (questões funcionais, remanejo ou lotação de professores, verbas para a escola, etc...); recursos humanos, entre outros assuntos.

Em relação aos questionários próprios, elaborados a partir dos objetivos da pesquisa e aplicados aos gestores escolares nos anos de 2011 e 2012, foram considerados dois blocos de questões: um bloco que dava conta do cotidiano escolar e sua relação com os resultados de aprendizagem dos discentes e outro bloco com os principais desafios que o gestor escolar enfrentava.

Já no que concerne à pesquisa de opinião aplicada a todos os professores da rede nos anos de 2013 e 2014, a mesma adotou como centralidade os processos de formação docente continuada, as percepções e expectativas dos docentes acerca dos mesmos, vinculados ao seu lugar social e profissional: o interior da escola e a imersão em seus processos próprios de gestão escolar.

Foi, igualmente, analisado o conteúdo dos relatórios anuais entregues pelas escolas ao final de cada ano letivo do recorte temporal estabelecido. Tais relatórios são elaborados por solicitação da mantenedora e contém o registro da avaliação da escola (mais especificamente da equipe de gestão escolar), informando os principais acontecimentos e as percepções/avaliações dos gestores sobre o cotidiano da escola e os episódios ao longo do ano. 
Nestes relatórios, há questões de foro estrutural, como proposições de ações para a mantenedora; avaliações circunstanciadas sobre os serviços de apoio prestados pela mantenedora; descrição do desempenho escolar dos alunos com o estabelecimento das possíveis causas para casos de evasão e repetência, mas também há questões de ordem do cotidiano, como relatos de fatos que tenham ocorrido na escola, tais como o fechamento de uma turma, a licença gestante de uma professora, as ações de adaptação dos alunos novos, palestras específicas ministradas na escola, etc...

O Calendário Escolar trata-se de um documento institucional elaborado em cada uma das escolas, respeitados alguns indicadores comuns, como início e término do ano letivo, bem como períodos de recesso. Tais calendários apresentam informações sobre: nominata da equipe gestora; nominata dos professores e suas respectivas funções na escola; número de turmas por ano escolar; número de alunos por turma; agendas de reuniões pedagógicas e/ou administrativas em cada escola; eventos festivos (festas juninas, celebrações de datas comemorativas, aniversário da escola, feira cultural/literária, etc...), horário de início e término das atividades em cada turno de trabalho escolar. Estes calendários precisam ser aprovados em duas instâncias: primeiro precisam da aprovação da comunidade escolar, em assembleia convocada para este fim. Sequencialmente, a escola precisa submeter o seu calendário ao crivo da mantenedora, que autoriza ou não a execução do referido calendário.

Por fim, foram examinados os resultados das avaliações em larga escala refletidos também nos índices de aprovação/reprovação e evasão e no Índice de Desenvolvimento da Educação Básica (IDEB) de cada escola.

Os elementos empíricos coletados foram cotejados por uma revisão bibliográfica, confrontada com uma pesquisa documental que trilhou estudos já realizados, visando o acúmulo de conhecimento em relação ao problema de pesquisa.

Cada documento selecionado forneceu dados que permitiram a organização de categorias operacionais de trabalho. A partir dessas categorias, foram mapeados os mecanismos de gestão presentes na escola, tais como: conselhos de classe, relação com a mantenedora, estruturas internas de gestão (eleições de diretores; conselhos escolares, conselhos de classe...) e mobilização do Projeto Pedagógico da escola, considerando que estes mecanismos interfeririam no cotidiano escolar, nos processos decisórios e de gestão e, por conseguinte, na qualidade da educação. 


\section{PROBLEMATIZANDO OS ACHADOS DA PESQUISA}

Com base nas categorias de análise estruturadas a partir dos documentos examinados, chegou-se ao seguinte resultado: é possível afirmar que há vínculos palpáveis entre a gestão escolar e a qualidade da educação, tais vínculos podem ser mapeados e, consequentemente, problematizados a partir de indicadores endógenos, como: práticas de gestão, sujeitos e cotidiano escolar, bem como de indicadores exógenos, constituídos pelas estruturas burocráticas da rede de escolas, os processos de formação docente e as avaliações em larga escala.

Buscando apresentar, em linhas gerais, as principais sistematizações da pesquisa, cumpre informar os achados empíricos em relação aos indicadores internos ou endógenos. Tais indicadores podem ser arrolados a partir de três dimensões: a) práticas de gestão escolar, que compreendem aspectos do ritual próprio da gestão, como reuniões administrativas e/ou pedagógicas, divisão de tarefas entre a equipe gestora e composição das estruturas e serviços de gestão escolar; b) sujeitos, representados por comunidade escolar (gestores, professores, funcionários, alunos, pais e comunidade em geral) e a participação de cada um na gestão escolar e, por fim, c) cotidiano escolar, entendido como a descrição das situações específicas da escola e dos seus rituais, como organização do pátio, hora do intervalo, momentos de recreação e lazer, além de dinâmicas de serviços como alimentação escolar e biblioteca.

Cada uma das três dimensões acima descritas se caracteriza como indicador por produzir informações reiteradas, que permitem descortinar o universo interno da escola e o impacto da gestão nos processos pedagógicos ocorridos no interior da unidade educativa.

No que diz respeito às "práticas de gestão escolar", é possível afirmar que os ritos institucionais estão presentes em todas as 35 escolas, com maior ou menor intensidade, produzindo situações organizacionais que se traduzem em (im)possibilidades para a qualidade da educação.

Concorrem - mas não exclusivamente -, para o tracejo deste indicador, condições como a habilidade de planejamento e liderança do gestor; a capacidade de mobilizar a comunidade escolar em torno de um projeto coletivo, agregando vontades individuais; organização e apresentação dos materiais e documentos institucionais, etc.

Neste indicador, a regularidade e a pauta prévia de reuniões administrativas e pedagógicas no âmbito da escola, oferecem pistas sobre as formas institucionais de preparo da equipe gestora. Quando as reuniões internas da escola não existem, não são regulares ou existem apenas com caráter de encaminhamento e repasse 
de avisos, podemos considerar que o indicador "práticas de gestão escolar" apresenta problemas que concorrem para desempenhos escolares insatisfatórios.

Quanto ao indicador "sujeitos", é possível mapear as escolas onde a figura do (a) diretor (a) se sobrepõe sobre os demais membros da equipe gestora e da comunidade escolar. Esta centralização resulta na manutenção de uma imagem de hierarquia, de diferenciação das funções desempenhadas por cada um dos membros da comunidade escolar. Este aparente distanciamento entre membros da comunidade escolar alimenta um distanciamento ainda maior entre a mantenedora e a maioria dos professores da rede (PESQUISA DE OPINIÃO, 2013). Os professores, quando têm alguma dúvida sobre os processos pedagógicos que são desenvolvidos no interior da escola recorrem, com primazia e quase que exclusivamente, aos gestores escolares e estes, se considerarem conveniente, recorrem aos serviços e subsídios da mantenedora, geralmente na condição de porta-vozes entre os docentes e a mantenedora.

Alguns gestores, entretanto, colocam-se na condição de líderes da escola, papel que fica evidente tanto nos questionários aplicados à equipe gestora (2011-2012) quanto nos relatórios anuais. Esta função de liderança parece estar orientada

[...] para a dinamização das relações interpessoais, para o desenvolvimento da escola como comunidades democráticas, para a transformação das práticas profissionais, para a gestão das redes de conhecimentos, para o empreendimento da mudança (BARROSO, 2000, p. 174).

Já o indicador "cotidiano escolar" foi o que apresentou maior grau de dificuldade em sua delimitação. Pouco se sabe, de fato, sobre as minúcias do funcionamento interno das escolas da rede. Poucos dados e detalhamentos são publicizados de maneira oficial e ficam à disposição de uma análise externa. As escolas pouco expõem do seu cotidiano nos documentos oficiais. Estes documentos são elaborados com relativo rigor, deixando patente apenas o que é necessário ou requerido. Também parecem não concordar com nenhum tipo de intromissão da mantenedora em seus assuntos de foro institucional (QUESTIONÁRIOS 2011). Alguns detalhes puderam ser pinçados dos questionários aplicados aos gestores (2011-2012), das atas das reuniões e, em alguma medida, dos relatórios finais (sobretudo na parte dedicada a avaliações gerais).

Podemos afirmar que há, além dos aportes legais, processos cotidianos que ocorrem no interior das escolas e assinalam consideravelmente as fronteiras entre escolas constituintes da mesma rede de ensino, pois "cada escola, mesmo 
imersa num movimento histórico de amplo alcance, é sempre uma versão local e particular desse movimento" (ROCKWELL; EZPELETA, 2007, p.133).

Dentre os poucos dados se sabe, por exemplo, que há uma insistência na comparação da escola como um grande núcleo familiar. Nos relatórios de final de ano, as equipes gestoras insistem, com força, na imagem da escola como uma família para professores e alunos. O uso de termos como "nossa escola"; "somos uma grande família", "nós aqui no bairro" entre outros chavões que denotam posse, são relativamente comuns nos relatórios mencionados. De igual maneira, eventuais problemas também são tratados nesta condição doméstica: "o aluno fulano não se adaptou a nossa forma..."; “uma professora pediu remanejo por não se ajustar ao projeto pedagógico da nossa escola".

Outra questão premente e de fácil mensuração diz respeito ao 'tarefismo' no qual gestores escolares denunciam abarrotar seu cotidiano escolar. Nos questionários aplicados (2011 e 2012), tal questão é recorrente e unânime, transparecendo um dia-a-dia cheio de tarefas e com pouco espaço para planejamentos e atividades educativas.

Entretanto, este queixume não aparece em todos os relatórios. Como explicar que algumas gestões escolares sentem-se de tal forma pressionadas pelas demandas contextuais e pelas tarefas ordinárias, a ponto de materializar este desconforto em um relatório oficial entregue pela mantenedora, enquanto outras escolas não comentam este 'tarefismo' ordinário? A resposta a esta aparente contradição reside na seguinte lógica:

O ordenamento jurídico-burocrático e as políticas produzem as diretrizes para
o modo de existência da escola na condição dos sistemas e redes escolares, das
variadas naturezas escolares atualmente existentes. No entanto, as diretrizes não
se reproduzem concretamente tal qual são enunciadas e propostas ou mesmo
importas no plano superestrutural. A organização da esfera educacional e de
cada instituição escolar é única, mesmo que ela mantenha relações de identidade
com outras instituições da mesma natureza (SILVA JR; FERRETTI, 2004, p. 58).

Justo por esta razão, toda a tentativa de compreensão sobre os fenômenos mais velados e atípicos no processo de gestão escolar pode levar a explicações sobre descompassos entre os discursos institucionais construídos e os indicadores de foro quantitativo produzidos por esta mesma instituição.

No que tange aos indicadores externos ou exógenos, estes são constituídos por igualmente três dimensões: a) estruturas burocráticas; b) processos de formação docente e, c) avaliações em larga escala.

No que se refere às "estruturas burocráticas", entendidas como os órgãos do sistema de ensino aos quais as escolas se subordinam, bem como as demandas específicas produzidas por estes órgãos, fica claro o distanciamento entre as 
escolas e, especialmente, o órgão administrativo do sistema, no caso, a Secretaria Municipal de Educação. Muitos relatórios narram, de forma fria e convencional, a relação estabelecida com a secretaria. Repleta de formalidades ou ausências, as atas das reuniões também demonstram esta distância entre mantenedora e mantidas (CADERNO DE ATAS, 2010-2014).

Entretanto, as diferentes possibilidades de relação com a mantenedora não conseguem indicar, isoladamente, como se processam as dinâmicas de gestão interna da escola, uma vez que...

\begin{abstract}
Não basta alterar as regras formais para mudar as realidades escolares, e estas mudam, com frequência, mesmo quando as primeiras se mantêm inalteradas. Ou seja, não são apenas os modelos decretados que influenciam as práticas de gestão; estas práticas são influenciadas por múltiplos factores, objectivos, interesses, circunstâncias etc., que, por sua vez, não deixam de influenciar o entendimento e até a produção dos modelos decretados. E, assim, as diversas realidades escolares não se transformam automaticamente por simples mudança dos modelos decretados, como também a mera manutenção destes não assegurará necessariamente a cristalização de tais realidades (LIMA, 2001, p. 112).
\end{abstract}

Os "processos de formação docente continuada" figuram como indicadores que compõem o quadro multifatorial que vincula a gestão escolar com a qualidade da educação a partir de dois pontos: um primeiro ponto tratase do considerável número de professores com formação qualificada na rede em tela. Dos 1.223 docentes atuando na referida rede em 2013, apenas 1,8\% não possuíam curso de nível superior (LEVANTAMENTOS ESTATÍSTICOS, 2013)e em contraposição, 59\% dos professores apresentam formação em nível de pós graduação lato e stricto sensu.

Outro dado que auxilia na caracterização do indicador diz respeito às equipes gestoras e sua formação. Das 35 escolas de ensino fundamental, 07 apresentam em seus quadros de gestores pessoal com formação em nível de pós-graduação stricto sensu. As demais contam com profissionais qualificados em especializações como Especialização em Supervisão Escolar, Especialização em Orientação Educacional ou Especialização em Gestão Escolar.

No que concerne à formação continuada proporcionada pela mantenedora - de acordo com a LDB 9.394/96, em seus artigos 13, 67 e 87 -, os últimos quatro anos foram marcados pela metodologia das sessões ou grupos de estudos temáticos. Entretanto, os dados advindos tanto dos relatórios anuais, quanto da pesquisa de opinião realizada em 2013, mostram que há um visível esgotamento dos processos de formação docente continuada na rede examinada.

Vários fatores são apontados como responsáveis por este esgotamento, a considerar: a excessiva presença de assessores (palestrantes, painelistas, 
oficineiros) vinculados prioritariamente a uma das Instituições de Ensino Superior da região; a exaustão de temas teóricos, supostamente sem respaldo no cotidiano escolar; o fato dos encontros serem compulsórios e, em relevo, o pouco envolvimento dos professores nas decisões acerca da formação continuada.

Todos estes indicadores são potencializados a partir dos resultados obtidos pelas unidades educativas quando da realização de "avaliações em larga escala". Há nítidas relações entre todos ou parte dos demais indicadores e o resultado obtido pelas escolas (RELATÓRIO DE PESQUISA, 2014).

Mais do que isso, há uma aparente consciência de que os resultados das avaliações externas não são fruto apenas do desempenho dos alunos, mas de um conjunto de fatores fortemente delineados pela gestão escolar. Tal consciência se expressa em um arrazoado de desculpas ou culpabilizações, materializado em alguns dos relatórios anuais de escolas cujo IDEB ou o resultado na Prova Brasil tenha sido deficitário. Em contrapartida, escolas com IDEB em ascensão e com bons resultados na Prova Brasil tecem costumam tecer comentários elogiosos ao trabalho dos professores e a condução do trabalho pedagógico por parte dos gestores escolares.

Ainda que exista o entendimento de que um (a) gestor (a) e sua equipe não podem conduzir a escola sozinhos, a busca por culpados pelos resultados da escola pode enveredar por um caminho paradoxal, colocando unicamente em fatores externos a eventual culpa por resultados insuficientes: "a comunidade é muito carente"; "faltou professor de matemática"; "a professora adoeceu"; "a secretaria não mandou professor de reforço escolar"; "os alunos não estudaram", entre outras estratégias de culpabilização externas.

\begin{abstract}
Não se quer dizer com isso que o sucesso da escola reside unicamente na pessoa do gestor ou em uma estrutura administrativa autocrática na qual ele centraliza todas as decisões. Ao contrário, trata-se de entender o papel do gestor como líder cooperativo, o de alguém que consegue aglutinar as aspirações, os desejos, as expectativas da comunidade escolar e articular a adesão e a participação de todos os segmentos da escola na gestão em um projeto comum. O diretor não pode ater-se apenas às questões administrativas. Como dirigente, cabe-lhe ter uma visão de conjunto e uma atuação que apreenda a escola em seus aspectos pedagógicos, administrativos, financeiros e culturais (LIBÂNEO, 2005, p.332)
\end{abstract}

Assim, em alguns casos, a gestão escolar pode tecer argumentos no sentido de eximir-se de quaisquer responsabilidades sobre os resultados de aprendizagem advindos dos processos pedagógicos ocorridos no interior da escola, ora desconsiderando o próprio protagonismo, colocando-se como expectador dos processos internos da escola; ora buscando insistentemente culpados. 


\section{CONCLUSÃO}

Diante do objetivo operacional deste texto expresso pela apresentação, em linhas gerais, das principais sistematizações da pesquisa em debate, é possível afirmar que há vínculos materiais e mensuráveis entre gestão escolar e qualidade da educação básica.

Pela pesquisa empírica empreendida, condições multifatoriais afetam a qualidade da educação e estas condições estão, em larga medida, atreladas a natureza, aos princípios e as dinâmicas de gestão escolar.

Assim, as escolas que mostram um desempenho satisfatório nas avaliações em larga escala, repercutindo também nos números do IDEB, são as escolas que apresentam uma série de indicadores de vínculo entre a gestão e a qualidade da educação, como: a) práticas de gestão escolar otimizadas pela organização e racionalidade administrativa; b) equipe gestora qualificada; c) relação de diálogo franco entre a mantenedora e as escolas componentes da rede pública; d) cotidiano escolar organizado com base no diálogo e na participação comprometida e profissional e, e) professores qualificados e partícipes dos processos de formação docente continuada, para além da frequência compulsória ou da praxe funcional.

A compatibilização de interesses e a construção de um projeto comum (BARROSO, 2000) para a escola passam por decisões de gestão que implicam conceber a mesma como uma ação de natureza profissional e pedagógica, que expressa mais do que a condução administrativa de uma unidade educativa, mas a real possibilidade de vincular esta atividade à qualidade da educação em escolas pública.

Assume-se, por fim, que a identificação, descrição e problematização dos indicadores se constituem em subsídio com potencial de colaborar para a qualidade dos processos pedagógicos acionados no interior da escola, bem como inolvidável etapa dos estudos apresentados, visando a continuidade da pesquisa em tela: a proposição de uma matriz de referência (quadro de desempenho) para a análise do funcionamento interno de equipes gestoras em situações materiais e contextuais, vinculadas a redes e sistemas públicos de ensino. 


\section{REFERÊNCIAS}

BARROSO, J. Autonomia das escolas: da modernização da gestão ao aprofundamento da democracia. In: COSTA, J. A; MENDES, A. N.; VENTURA, A. (Org.). Liderança e estratégia nas organizações escolares. Portugal: Aveiro Universidade, 2000.

JULIA, D. A cultura escolar como objeto histórico. Revista Brasileira de História da Educação, Campinas, v. 1, n. 1, pp. 9-44, jan/jun 2001.

LIBÂNEO, J.C.; OLIVEIRA, J.F.;TOSCHI, M.S. Educação escolar, políticas, estruturas e organização. $2^{\mathrm{a}}$ ed. São Paulo: Cortez, 2005.

LIMA, L.C. A escola como organização educativa: uma abordagem sociológica. São Paulo: Cortez, 2001.

. A 'escola' como categoria na pesquisa em educação. Educação: Unisinos, v. 12 , n. 2 , pp. 82-88, mai/ago 2008.

MINAYO, M. C. de S. (Org). Pesquisa social: teoria, método e criatividade. Petrópolis, RJ: Vozes, 2002.

ROCKWELL, Elsie; EZPELETA, Justa. A escola: relato de um processo inacabado de construção. Revista Currículo sem Fronteiras, v. 7, n.2, pp.131147, jul./dez 2007.

SECRETARIA MUNICIPAL DE EDUCAÇÃO. Levantamentos Estatísticos, Setor de registros escolares, Coordenadoria de Administração, 2014.

SECRETARIA MUNICIPAL DE EDUCAÇÃO. Livro de Atas das Reuniões entre a Secretaria e os gestores escolares, 2010; 2011; 2012; 2013, 2014.

SECRETARIA MUNICIPAL DE EDUCAÇÃO. Pesquisa de opinião, 2013.

SECRETARIA MUNICIPAL DE EDUCAÇÃO. Relatórios anuais das escolas de ensino fundamental, 2010; 2011; 2012; 2013.

SILVA JR., J. dos R. e FERRETTI, C. J. O institucional, a organização e a cultura da escola. São Paulo: Xamã, 2004.

UNIVERSIDADE DE PASSO FUNDO. Relatório final de Pesquisa. Gestão e qualidade da educação: um diálogo possível. CNPq, 2014.

VIEIRA, S L. Educação básica: política e gestão da escola. Brasília: Liber Livro, 2009. 
ROSIMAR SERENA SIQUEIRA ESQUINSANI é doutora em Educação pela Universidade do Vale do Rio dos Sinos - UNISINOS, professora do Programa de Pós-graduação da Universidade de Passo Fundo / UPF e pesquisadora do CNPq. E-mail: rosimaresquinsani@upf.br

CARMEM LÚCIA ALBRECHT DA SILVEIRA é mestra em Educação pela UPFRS, pedagoga e professora de Educação Básica da rede pública municipal de Carazinho/RS. E-mail: carmem.albrecht@hotmail.com

Recebido em fevereiro de 2015

Aprovado em março de 2015 